\title{
๖Variable Nordic Seas Inflow Linked to Shifts in North Atlantic Circulation 0
}

\author{
Helene Asbjørnsen, ${ }^{\mathrm{a}, \mathrm{b}}$ Helen L. Johnson, ${ }^{\mathrm{c}}$ AND MARius ÅRThun ${ }^{\mathrm{a}, \mathrm{b}}$ \\ ${ }^{a}$ Geophysical Institute, University of Bergen, Bergen, Norway \\ ${ }^{\mathrm{b}}$ Bjerknes Centre for Climate Research, Bergen, Norway \\ ${ }^{\mathrm{c}}$ Department of Earth Sciences, University of Oxford, Oxford, United Kingdom
}

(Manuscript received 27 November 2020, in final form 27 May 2021)

\begin{abstract}
The inflow across the Iceland-Scotland Ridge determines the amount of heat supplied to the Nordic seas from the subpolar North Atlantic (SPNA). Consequently, variable inflow properties and volume transport at the ridge influence marine ecosystems and sea ice extent farther north. Here, we identify the upstream pathways of the Nordic seas inflow and assess the mechanisms responsible for interannual inflow variability. Using an eddy-permitting ocean model hindcast and a Lagrangian analysis tool, numerical particles are released at the ridge during 1986-2015 and tracked backward in time. We find an inflow that is well mixed in terms of its properties, where $64 \%$ comes from the subtropics and $26 \%$ has a subpolar or Arctic origin. The local instantaneous response to the NAO is important for the overall transport of both subtropical and Arctic-origin waters at the ridge. In the years before reaching the ridge, the subtropical particles are influenced by atmospheric circulation anomalies in the gyre boundary region and over the SPNA, forcing shifts in the North Atlantic Current (NAC) and the Subpolar Front. An equatorward-shifted NAC and westward-shifted Subpolar Front correspond to a warmer, more saline inflow. Atmospheric circulation anomalies over the SPNA also affect the amount of Arctic-origin water rerouted from the Labrador Current toward the Nordic seas. A high transport of Arctic-origin water is associated with a colder, fresher inflow across the Iceland-Scotland Ridge. The results thus demonstrate the importance of gyre dynamics and wind forcing in affecting the Nordic seas inflow properties and volume transport.
\end{abstract}

KEYWORDS: North Atlantic Ocean; Ocean circulation; Ocean dynamics; Interannual variability

\section{Introduction}

Warm and saline Atlantic water supplied by the North Atlantic Current (NAC) flows into the Nordic seas over the Iceland-Scotland Ridge (Fig. 1). Heat transport variability at the ridge is a major driver of heat content variability in the Nordic seas (Mork et al. 2014; Asbjørnsen et al. 2019), which in turn affects marine ecosystems (Hátún et al. 2009; Årthun et al. 2018a), Arctic sea ice extent (Yeager et al. 2015; Årthun et al. 2012), and continental climate in northwestern Europe (Sutton and Dong 2012; Årthun et al. 2018b). Additionally, the saline Atlantic water transported poleward facilitates dense water formation in the Nordic seas and Barents Sea, and is therefore an integral part of the thermohaline circulation (Eldevik and Nilsen 2013; Chafik and Rossby 2019). While the inflow across the Iceland-Scotland Ridge is well observed and much studied due to its importance for high-latitude climate (e.g., Hansen and Østerhus 2000; Chafik 2012; Bringedal et al. 2018), the relationship between variability in hydrography and volume transport at the ridge and large-scale ocean circulation changes in the North Atlantic is still debated (e.g., Glessmer et al. 2014;

๑ Denotes content that is immediately available upon publication as open access.

Supplemental information related to this paper is available at the Journals Online website: https://doi.org/10.1175/JCLI-D-200917.s1.

Corresponding author: Helene Asbjørnsen, h.asbjornsen@uib.no
Holliday et al. 2020; Kenigson and Timmermans 2021). Untangling such relationships has implications for the predictability of Nordic seas inflow variability and the downstream impacts.

The NAC is an extension of the Gulf Stream and represents the northern boundary of the Subtropical Gyre (STG), with the colder and fresher Subpolar Gyre (SPG) to the north (Rossby 1996). In reaching the topographic barrier that is the Iceland-Scotland Ridge, the NAC flows via the Rockall Trough through the Faroe-Shetland Channel or via the Iceland Basin and over the Iceland-Faroe Ridge (Daniault et al. 2016; Houpert et al. 2018). The flow across the Iceland-Scotland Ridge is driven by both momentum and buoyancy forcing, and variability on a broad range of time scales is seen in observations (Bringedal et al. 2018; Østerhus et al. 2019). In this study, we focus on interannual to decadal variability in the strength and properties of the Nordic seas inflow and associated mechanisms, though we recognize that there is pronounced variability on shorter time scales related to adjustments to local wind stress (Sherwin et al. 2008) and mesoscale activity (Zhao et al. 2018).

Interannual variability in the Nordic seas inflow has previously been linked to large-scale wind forcing associated with the North Atlantic Oscillation (NAO; e.g., Zhang et al. 2004; Sand $\varnothing$ et al. 2012; Bringedal et al. 2018). Being the primary mode of atmospheric variability in the North Atlantic region

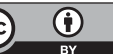

This article is licensed under a Creative Commons Attribution 4.0 license (http://creativecommons.org/ licenses/by/4.0/).

DOI: 10.1175/JCLI-D-20-0917.1 


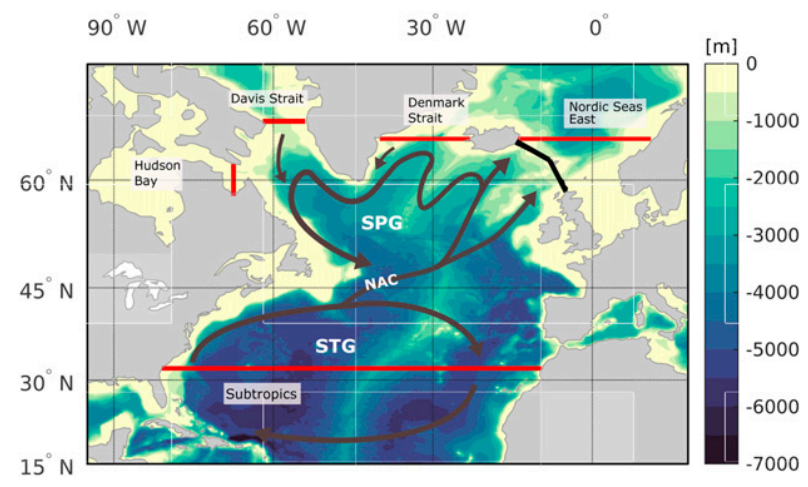

FIG. 1. Bathymetry of the North Atlantic Ocean. The particle release section at the Iceland-Scotland Ridge is marked in black, and the source region definitions are shown in red: subtropics $\left(32^{\circ} \mathrm{N}\right)$, Hudson Bay $\left(67.5^{\circ} \mathrm{W}\right)$, Davis Strait $\left(67^{\circ} \mathrm{N}\right)$, Denmark Strait $\left(65^{\circ} \mathrm{N}\right)$, and Nordic seas East $\left(65^{\circ} \mathrm{N}\right)$. The main upper-ocean circulation features are indicated by arrows.

(Hurrell 1995), the NAO drives ocean circulation changes and surface heat flux anomalies in the North Atlantic Ocean (e.g., Marshall et al. 2001; Bersch 2002; Sarafanov 2009). A positive NAO phase (here $\mathrm{NAO}^{+}$) is, for instance, known to cause elevated heat loss over the subpolar North Atlantic (SPNA) and intensified convection in the Labrador Sea (e.g., Sarafanov 2009). Furthermore, both analytical (Marshall et al. 2001) and numerical models (Herbaut and Houssais 2009; Eden and Willebrand 2001) show an anticyclonic circulation anomaly in the intergyre region (termed an "intergyre-gyre") as an oceanic response to wind stress anomalies related to $\mathrm{NAO}^{+}$conditions, resulting in advection of cold and fresh water eastward toward the Iceland-Scotland Ridge.

Several studies highlight the role of the SPG in controlling the composition and strength of the Nordic seas inflow through shifts in the Subpolar Front and, thus, the advective pathways toward the Iceland-Scotland Ridge. Specifically, a weak SPG has been associated with a northwestward-shifted Subpolar Front, high NAC transport of subtropical waters, and a more saline inflow (Hátún et al. 2005; Koul et al. 2020). Variable STG-SPG exchanges have furthermore been linked to North Atlantic wind stress curl variability (not always attributable to the NAO) modulating the gyres. For instance, Häkkinen et al. (2011) find that a weakened climatological positive wind stress curl pattern over the SPNA is linked to a weak SPG and increased northward penetration of subtropical water at nearsurface depths.

The Nordic seas inflow is also subject to decadal trends in the SPNA heat content and freshwater content. During the 1990s and early 2000s the SPNA was warming, followed by a trend reversal and cooling after 2005 (Robson et al. 2016; Piecuch et al. 2017). The 2005 trend reversal has been explained by both changes in overturning circulation (Robson et al. 2016) and anomalous gyre circulation due to changes in the wind stress curl (Piecuch et al. 2017). During 2012-16, a record-breaking freshening of the SPNA was observed (Holliday et al. 2020), which subsequently was also seen in the Nordic seas (Mork et al. 2019). Unlike the Great Salinity Anomaly of the late 1960s caused by enhanced freshwater export from the Arctic (Dickson et al. 1988), Holliday et al. (2020) explain the recent freshening by anomalous winter wind patterns rerouting Arctic-origin water in the Labrador Current off the continental shelf and into the subpolar basins. Kenigson and Timmermans (2021) argue that the freshening described in Holliday et al. (2020) can be explained by wind-driven displacements of the Subpolar Front due to persistent $\mathrm{NAO}^{+}$ conditions during 2014-16, without requiring the advection of rerouted Labrador Current water from the western basin.

In this study, we address the following two questions: 1) What are the pathways of subtropical and Arctic waters toward the Nordic seas, and how variable are these pathways? 2) What are the mechanisms responsible for a cold and fresh versus a warm and saline inflow? To answer these questions and explore the link between variability at the Iceland-Scotland Ridge and large-scale circulation anomalies in the North Atlantic, we use an eddy-permitting, global ocean hindcast simulation together with a Lagrangian analysis tool. The model framework and the Lagrangian experiment performed are described in section 2. Source regions and the upstream advective pathways of the Nordic seas inflow are identified and described in section 3. Transit times and along-path water mass modification are discussed in section 4 and section 5 . Volume transport variability and the associated atmospheric forcing are analyzed in section 6 and section 7. Finally, the main findings are summarized and discussed in section 8 .

\section{Methods}

\section{a. ORCA025}

The 5-day mean output of an ocean-ice model hindcast simulation based on ORCA025 is used to study the North Atlantic circulation over a period of 40 years. The ORCA025 configuration is developed by the Drakkar project (Bernard et al. 2006), and is a global, eddy-permitting configuration of the NEMO model (Madec et al. 2016) coupled to the thermodynamic Louvain-la-Neuve sea ice model, version 2 (LIM2; Bouillon et al. 2009). The hindcast simulation used spans 19582015, with no spinup. Here, we only consider data from 1976 to 2015. The ORCA025 grid is tripolar, with a $1 / 4^{\circ}$ horizontal resolution ( $27 \mathrm{~km}$ at the equator, $12 \mathrm{~km}$ in the Arctic), $75 \mathrm{un}$ evenly spaced vertical levels, and a partial step representation of bottom topography (Bernard et al. 2006). The Drakkar forcing set 5.2, constructed from ERA-Interim (Dee et al. 2011) and ERA-40 (Uppala et al. 2005) surface fields, is used as the atmospheric forcing. A detailed description of the forcing set is given in Dussin et al. (2016). The advection and diffusion schemes used in this ORCA025 configuration are described in Grégorio et al. (2015).

\section{b. ARIANE}

To evaluate the upstream pathways of the Nordic seas inflow, we use the Lagrangian analysis tool ARIANE (https:// stockage.univ-brest.fr/\% 7Egrima/Ariane/) for offline calculations of Lagrangian trajectories from the ORCA025 velocity fields. The ARIANE algorithm has been used extensively to 


\section{a) Observations}

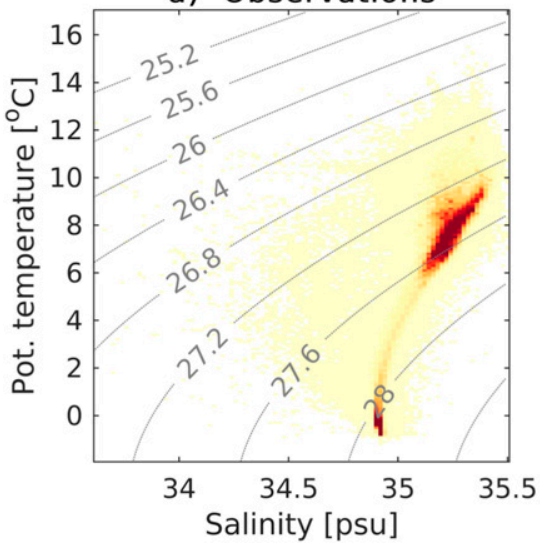

b) Eulerian

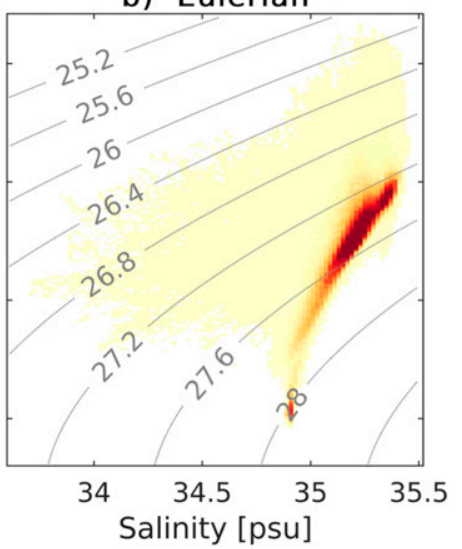

c) Lagrangian (inflow)

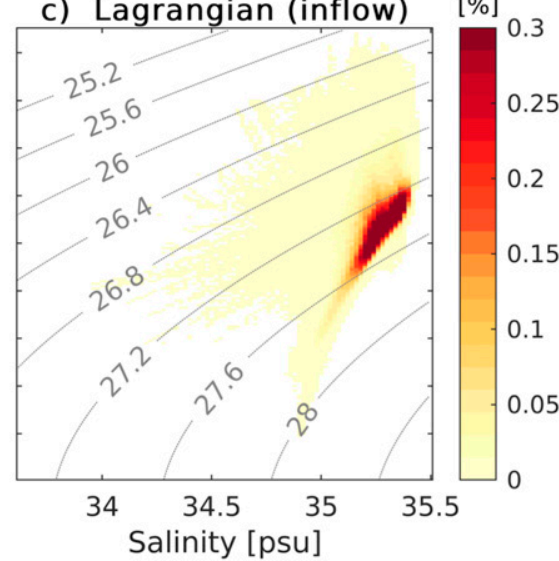

FIG. 2. Hydrographic properties at the Iceland-Scotland Ridge. Occurrence-weighted $T-S$ diagrams for the Iceland-Scotland Ridge in (a) observations (replotted from Eldevik and Nilsen 2013), (b) the ORCA025 fields, and (c) the Lagrangian framework from particle properties (inflow only). Particles are binned into $T-S$ classes at $0.1^{\circ} \mathrm{C}$ intervals between $-2^{\circ}$ and $17^{\circ} \mathrm{C}$, and 0.02 psu intervals between 33.60 and 35.50 psu. Potential density $(\sigma)$ is indicated by the dashed gray contour lines.

analyze the output of ocean general circulation models (OGCMs; e.g., Lique et al. 2010; de Boisséson et al. 2012; Desbruyères et al. 2013, 2015; Behrens et al. 2017; MacGilchrist et al. 2017; Kelly et al. 2019). ARIANE utilizes a purely advective scheme where streamlines are computed analytically, and represent true trajectories under the assumption of three-dimensional nondivergence and temporal stationarity over the sampling period (here 5 days). A comprehensive description of the ARIANE algorithm is given in Döös (1995) and Blanke and Raynaud (1997).

In our Lagrangian experiment, numerical particles are initialized at the Iceland-Scotland Ridge (Fig. 1) over a 30-yr period (1986-2015) and tracked backward in time for 10 years. The particles are released continuously in time and distributed in space to represent the full column of inflowing water at the ridge. The number of particles released in each grid cell of the vertical cross section along the ridge is scaled with the volume transport through that grid cell at the release time. A single particle represents a maximum of $0.01 \mathrm{~Sv}\left(1 \mathrm{~Sv} \equiv 10^{6} \mathrm{~m}^{3} \mathrm{~s}^{-1}\right)$, resulting in a sufficiently high number of released particles $(9.6$ million over 30 years) to achieve robust Lagrangian statistics (e.g., van Sebille et al. 2018; Jones et al. 2016). The inflow transport is highest in winter as seen in observations (Bringedal et al. 2018), and a larger number of particles are therefore released during the winter months. Particle volume is conserved along the individual trajectories, while particle properties (temperature and salinity) evolve according to the local Eulerian fields of the ocean model.

Because the Ariane scheme is purely advective, subgridscale processes parameterized in the ORCA025 configuration (such as diffusion and turbulent mixing) are not factored into the Lagrangian trajectory calculations (Wagner et al. 2019). However, these processes still affect the Eulerian temperature and salinity fields that the particles are translated through, and therefore indirectly the particle properties (Lique et al. 2010). The time-averaged fields used for offline trajectory calculations can smear out short-time, small-scale advective processes simulated by the OGCM, but errors associated with this are likely limited as long as the averaging period is no longer than a few days (Valdivieso Da Costa and Blanke 2004; Qin et al. 2014). Despite the aforementioned error sources, the close resemblance between the advective pathways of offline Lagrangian particles and the advective-diffusive pathways of online passive tracers found in previous studies is encouraging (Gillard et al. 2016; Wagner et al. 2019), and we consider the resolved velocity field to capture the main circulation features in the North Atlantic studied here.

\section{c. Model evaluation}

The realism of the advective pathways and along-path properties determined from the Lagrangian analysis relies on how well the North Atlantic circulation and water masses are simulated in the ORCA025 hindcast. Figure 2 shows a comparison between a large number of hydrographic observations at the Iceland-Scotland Ridge between 1950 and 2005 (replotted from Eldevik and Nilsen 2013), and temperature-salinity ( $T$ and $S$, respectively) properties in the ORCA025 hindcast within the Eulerian and Lagrangian frameworks for the period of particle releases (1986-2015). The ORCA025 hindcast simulation captures well the observed water mass properties at the Iceland-Scotland Ridge, with an Atlantic water core, dense overflow water, and a realistic spread in $T$ and $S$ (Figs. 2a-b).

Due to the complex topography at the Iceland-Scotland Ridge, simulating transports comparable to the observed ones is notoriously difficult, especially with coarse-resolution global climate models (Olsen et al. 2016; Heuzé and Årthun 2019). Østerhus et al. (2019) estimate the time-mean net volume transport between Iceland and Scotland in observations to be $4.5 \pm 1.9 \mathrm{~Sv}$ (1993-2015), with a net upper-ocean transport of $7.1 \pm 1.2 \mathrm{~Sv}$ into the Nordic seas and a dense overflow of $-2.6 \pm 0.7 \mathrm{~Sv}$. In comparison, the ORCA025 time-mean volume transport for the release section seen in Fig. 1 is $3.9 \mathrm{~Sv}$ (1986-2015), with an inflow of 9.8 Sv, and an upper-ocean outflow of $-3.8 \mathrm{~Sv}$, resulting in a net upper-ocean transport of $6.0 \mathrm{~Sv}$. Additionally, a dense overflow of $-2.1 \mathrm{~Sv}$ is found 
(defined as $\sigma>27.7$ in the model based on visual inspection of the density and velocity fields, and differing slightly from the observational definition). The simulated volume transports are within the observational range of uncertainty, and we therefore consider the ORCA025 hindcast to adequately capture the mean state at the Iceland-Scotland Ridge in terms of both volume transport and properties.

In the analysis presented here, the 5-day mean inflow (northeastward) and outflow (southwestward) transports are separated before computing the annual means. Any resolved northeastward mesoscale transport is therefore included in the inflow estimate, resulting in the annual mean inflow of $11.5 \mathrm{~Sv}$ seen in Fig. 3a (larger than the time-mean inflow of 9.8 Sv). Inflowing particles recirculated as an outflow directly after particle seeding are removed from the Lagrangian analysis. The transports and temperatures of the remaining particles reproduce the magnitude and variability of the Eulerian volume transport and transport weighted temperature calculated directly from the ORCA025 fields (Fig. 3), and are therefore representative of the inflowing water mass.

\section{Source regions and advective pathways}

To determine the upstream sources of the inflowing water masses at the Iceland-Scotland Ridge, a number of simple geographical criteria are defined (Fig. 1). The "subtropics" is defined as south of $32^{\circ} \mathrm{N}$. The "Denmark Strait" source region is defined as west of Iceland and north of $65^{\circ} \mathrm{N}$, while "Nordic seas East" is defined as east of Iceland and north of $65^{\circ} \mathrm{N}$. Finally, the "Hudson Bay" source region is west of $67.5^{\circ} \mathrm{W}$ in the Hudson Strait, and the "Davis Strait" source region is north of $67^{\circ} \mathrm{N}$ in the Davis Strait. A single particle can in principle visit several of the defined regions, but only the most recently visited region prior to reaching the Iceland-Scotland Ridge is registered as the source region in our analysis. Particles not fulfilling any source region criteria within the 10 years of tracking are registered as "residuals" and are representative of waters that have been in the SPNA (or Mediterranean Sea) for at least 10 years prior to flowing across the ridge.

To visualize the advective pathways toward the Nordic seas, we bin particle positions every 5 days over the full 10 years of tracking at $1^{\circ} \times 1^{\circ}$ (latitude $\times$ longitude) into histograms. The resulting particle probability density distribution seen in Fig. $4 \mathrm{a}$ are obtained by counting the number of particles occupying each bin at each time step, summing the particle counts for each bin over all time steps, and dividing by the total number of particle counts for all bins. The same procedure is repeated for particle subsets grouped according to the source region most recently visited prior to reaching the IcelandScotland Ridge. The resulting advective pathways are seen in Figs. 4b-f.

From Fig. 4a it is evident that the NAC is the most pronounced pathway, with the subtropics as the dominant source region. Particles routed through the Caribbean Sea and Gulf of Mexico feed the Gulf Stream and the NAC (Fig. 4b), consistent with previous studies (e.g., Fratantoni 2001; Bower et al. 2019). The dominance of the subtropics-NAC pathway is reflected in
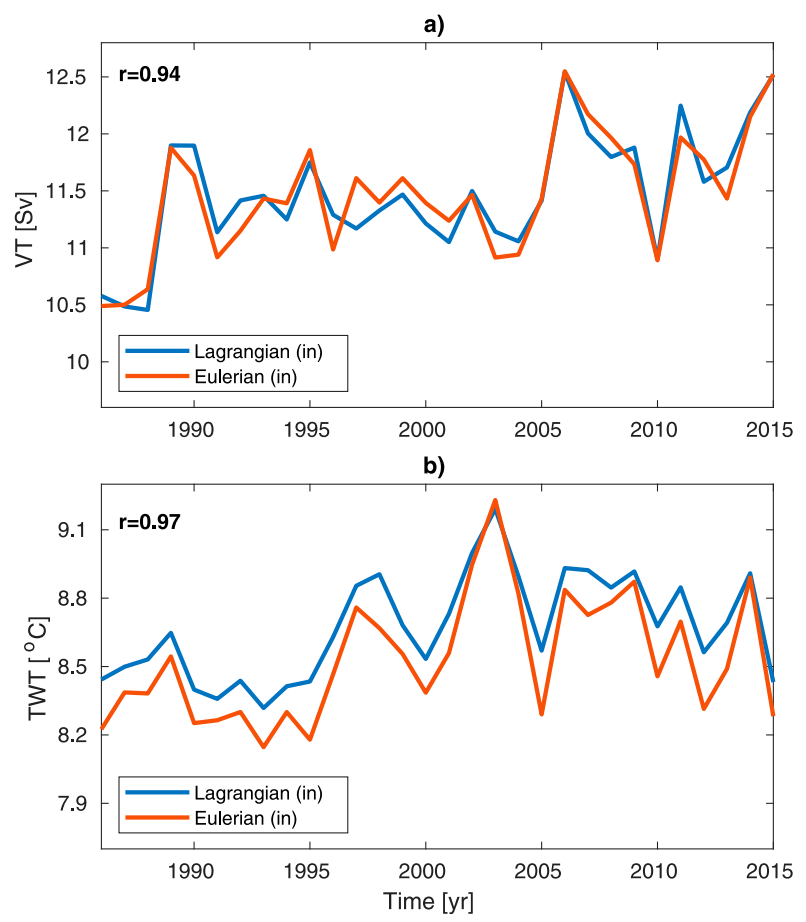

FIG. 3. Eulerian vs Lagrangian estimates of annual mean (a) inflow volume transport and (b) transport-weighted temperature at the Iceland-Scotland Ridge. The Eulerian transports are calculated directly from the ORCA025 fields.

the volume transport decomposition (Fig. 5), where on average $64 \%$ of the inflowing water at the Iceland-Scotland Ridge comes from the subtropics. Of the remaining inflow, 7\% comes from the Davis Strait or Hudson Bay, and 4\% comes from the Denmark Strait. Additionally, $10 \%$ of the inflow water comes from the Nordic seas East region north of the ridge, and the remaining $15 \%$ comes from the SPNA reservoir registering as the residual group. A statistically significant trend in the inflow transport is present over the 1986-2015 period $\left(0.03 \mathrm{~Sv} \mathrm{yr}^{-1}\right)$, mostly due to a positive trend in the transport of subtropical water.

As indicated by the particle depth evolution in Fig. 7a, Davis Strait and Hudson Bay are the main source regions for surface water at the ridge, making up $42 \%$ of the surface inflow while subtropical water only makes up 14\% (not shown). Particles coming from the Davis Strait or Hudson Bay typically flow at near-surface depths in the Labrador Current, before tracing out the southern boundary of the SPG and reaching the Iceland-Scotland Ridge close to the surface (Fig. 4c). We do, however, note that, because the trajectories are purely advective, particles are not redistributed in the vertical by turbulent mixing in the mixed layer. As a result, it is likely that the vertical displacement of these particles is underestimated, affecting the depth at which the particles cross the ridge. Limited surface connectivity between the subtropics and the Iceland-Scotland Ridge is nevertheless consistent with surface drifter observations (Brambilla and Talley 2006) and previous modeled Lagrangian pathways (e.g., Rypina et al. 2011; Foukal and Lozier 2016). 
a) All

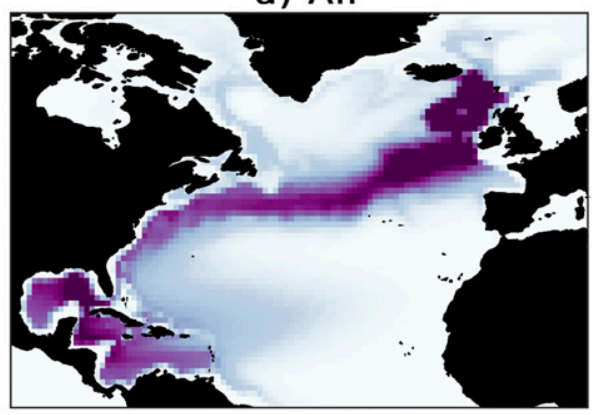

c) Davis \& Hudson straits

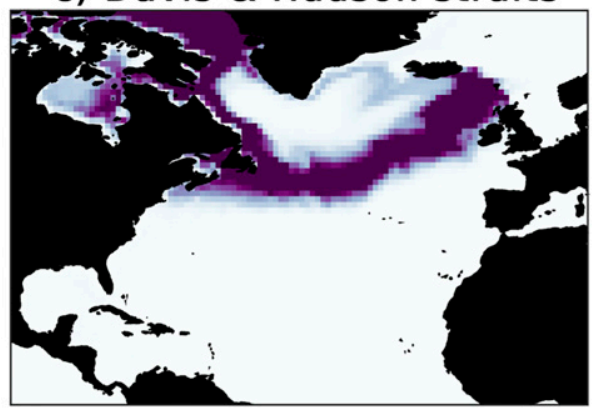

e) Nordic Seas East

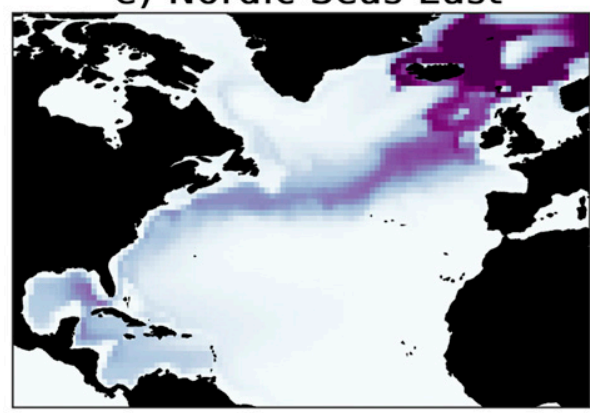

b) Subtropics

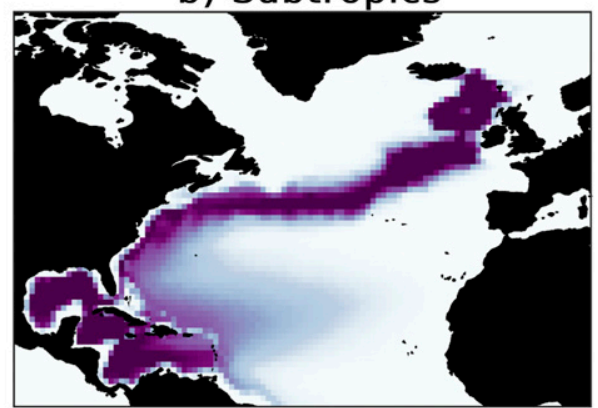

d) Denmark Strait

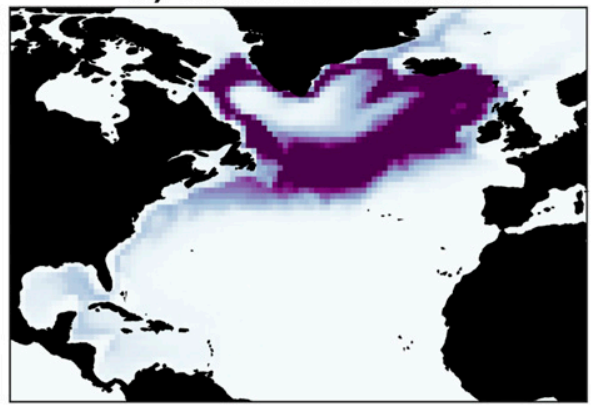

f) Residual

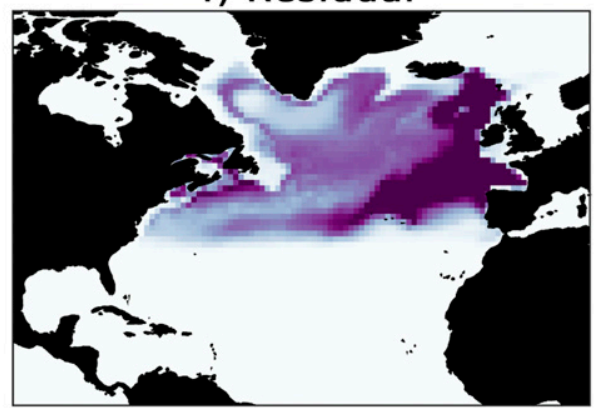

0.05

0.06

0.07

0.08

Particle probability density [\%]

FIG. 4. Advective pathways toward the Nordic seas. Particle probability density distribution from 10 years of tracking for (a) all inflowing particles between 1986 and 2015 and (b)-(f) particles subset by source region. The particle positions every 5 days over the 10 years of tracking are binned at $1^{\circ} \times 1^{\circ}$ into histograms and normalized by the total number of particle positions so that the probability densities in each panel sum to $100 \%$.

Shoaling isopycnals along the path of the Gulf Stream and NAC are believed to connect the STG to the SPG at subsurface depths, while a large part of the Gulf Stream surface water is recirculated into the STG (Burkholder and Lozier 2011; Bower et al. 2019).

The Denmark Strait source region captures particles that are circulating in the SPG before reaching the Iceland-Scotland Ridge (Fig. 4d). Some of the particles come from the Greenland Sea through the Denmark Strait (roughly 15\% have been north of $67^{\circ} \mathrm{N}$ ), while the rest register as the Denmark Strait source region when flowing along the northern boundary of the SPG. The large horizontal spread in the particle pathways at the southeastern boundary of the SPG is consistent with known variability in the SPG extent (e.g., Koul et al. 2020).

The Nordic seas East pathway might appear counterintuitive for an inflow into the Nordic seas (Fig. 4e) and is a result of a complex flow pattern at the Iceland-Scotland Ridge where particles cross the ridge as an outflow and are recirculated as an inflow at a later stage. Prior to reaching the ridge, most of these particles circulate within the Nordic seas at depth. A sizeable 


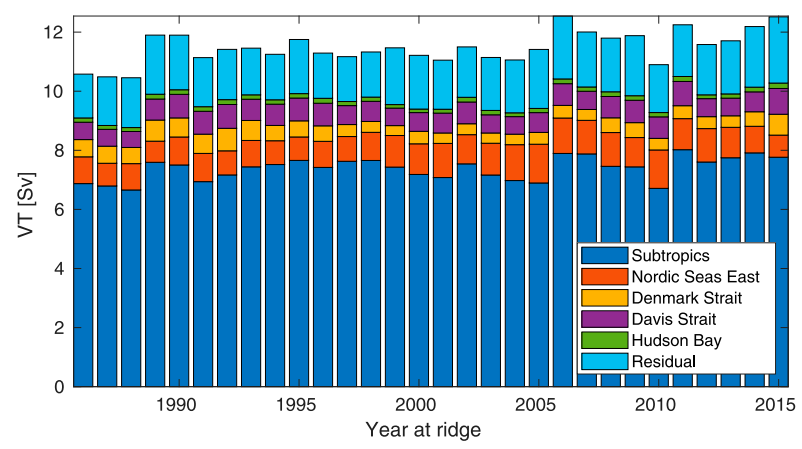

FIG. 5. Iceland-Scotland Ridge volume transport. Inflow volume transport for the particle release section at the Iceland-Scotland Ridge decomposed into contributions from the upstream source regions seen in Fig. 1.

fraction (roughly 35\%) have previously been south of the Denmark Strait, and flow east toward the ridge with the North Icelandic Irminger Current. Water from the Nordic seas East source region is colder and fresher than the water from the other source regions, and mostly flows across the ridge at depths below $100 \mathrm{~m}$ (not shown).

The trajectories of the particles within the residual group display a wide range of pathways (Fig. 4f); some circulate in the SPG before reaching the ridge, some progress slowly with the
NAC due to considerable eddying and meandering, and some move slowly along the European coast with the European Slope/Shelf Edge Current (Marsh et al. 2017). The residual group also includes particles coming from the Mediterranean, but the number of particles that have been east of Gibraltar within the 10 years of tracking is very low (less than $1 \%$ of the particles in the residual group).

\section{Transit times}

The median transit time to the ridge from the subtropics, Davis and Hudson Straits, and the Denmark Strait source regions is roughly 4 years (Fig. 6). There is, however, a large spread in particle transit times within each of the different advective pathways. For instance, the fastest particles coming from the subtropics take under 2 years to reach the Iceland-Scotland Ridge, while the slowest particles take the full 10 years of tracking to reach the ridge (Fig. 6a). The large spread in transit times is indicative of the different trajectories the particles follow within the defined advective pathways (e.g., different depths and along-path vertical displacements, eddying features, horizontal pathway shifts). Generally, particles crossing the ridge at depth have a longer transit time from their respective source region compared to particles reaching the ridge close to the surface.

A median transit time of $4-5$ years from the subtropics $\left(32^{\circ} \mathrm{N}\right.$ in Fig. 1 or box $A_{1}$ in Fig. 8b) to the ridge along the NAC is
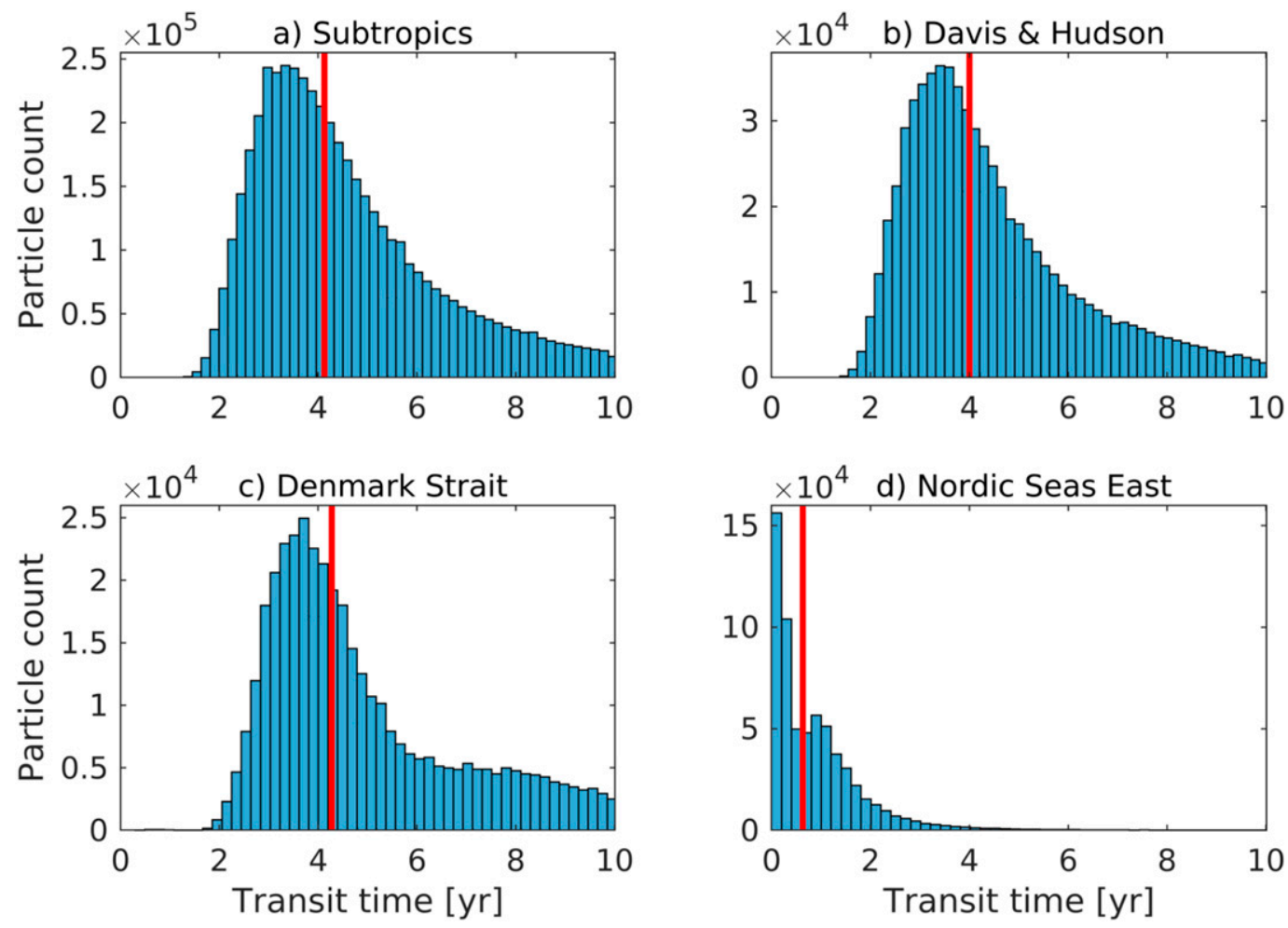

FIG. 6. Particle transit time distribution sorted by source region. The red lines mark the median transit time to the Iceland-Scotland Ridge from the source regions (subtropics: 4 years and 2 months; Davis and Hudson: 4 years; Denmark Strait: 4 years and 3 months; Nordic seas East: 8 months). Note different scales on $y$ axes for the different advective pathways. 

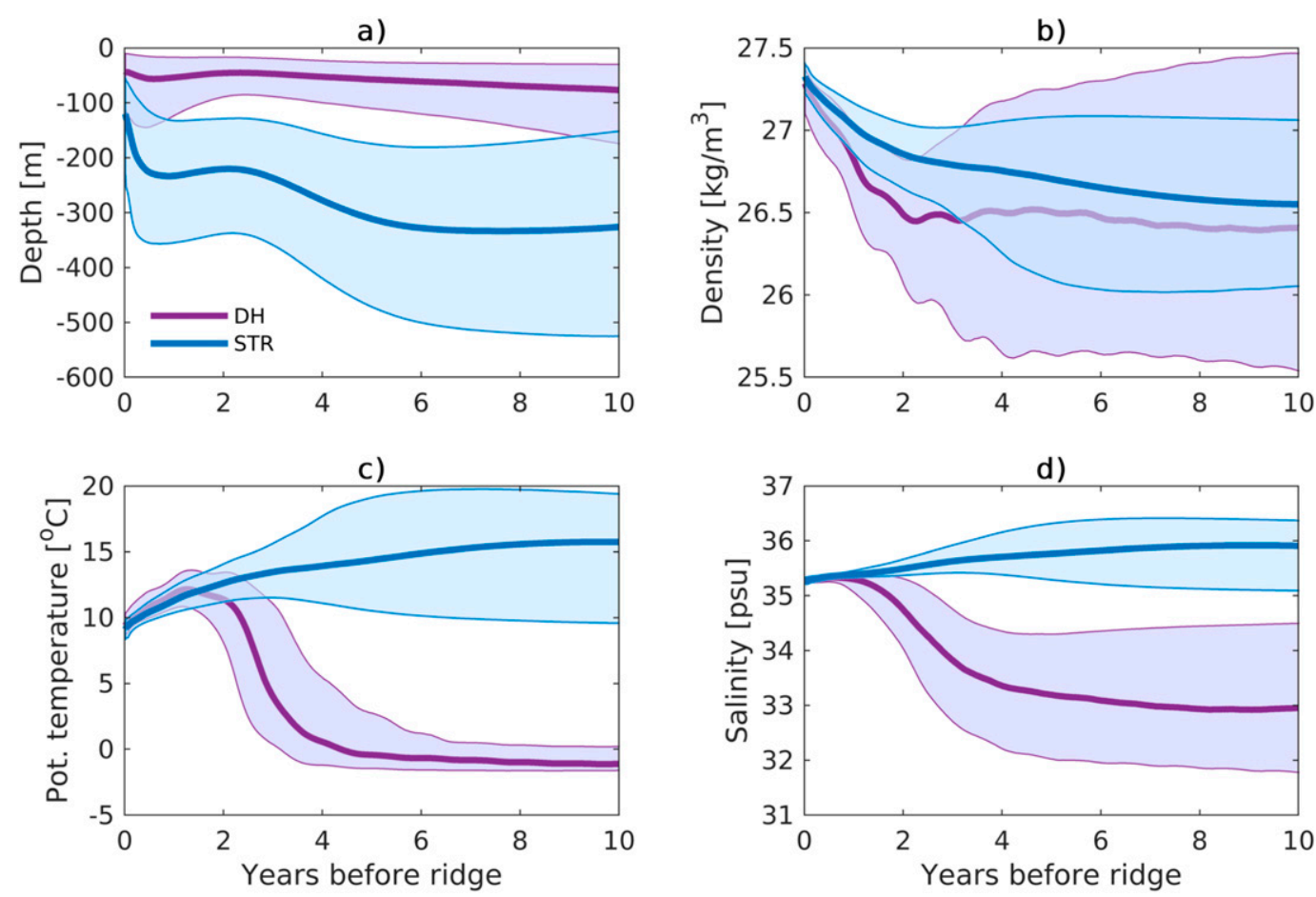

FIG. 7. Evolution of particle properties in time. Median (a) depth, (b) density, (c) potential temperature, and (d) salinity of particles from the subtropics (blue) and from the Davis and Hudson Straits (purple) over the 10 years prior to reaching the Iceland-Scotland Ridge. Shading marks the 25 th and 75 th percentiles to show the spread in particle properties within the defined pathways.

equivalent to a speed of roughly $4-5 \mathrm{~cm} \mathrm{~s}^{-1}$, which is in the range of the observed and modeled propagation speed of thermohaline anomalies (e.g., Sutton and Allen 1997; Chepurin and Carton 2012; Årthun et al. 2017). We find little interannual variability in the median transit times from the different source regions to the ridge (not shown), and therefore do not consider this a major source of variability for the Atlantic water inflow.

\section{Along-path water mass modification}

The inflowing water masses at the Iceland-Scotland Ridge are found to be well mixed in potential temperature and salinity. Figure 7 shows the considerable along-path water mass modification that occurs during the 10 years of tracking. The subtropical water experiences cooling and freshening on its pathway toward the ridge. The Arctic-origin water experiences warming and salinification, likely through lateral mixing with warmer and saltier waters, until it reaches the eastern SPNA, after which the water cools as part of a near uniform water mass before reaching the ridge (Fig. 8). As expressed in Fig. 8, the convergence in TS properties of subtropical water and Arctic-origin water happens south of the ridge in the eastern SPNA. Consistent with observations, the simulated winter mixed-layers in the eastern SPNA are almost as deep as the mean sill depth (400-500 m; Fig. S3), and the region is known for vigorous water mass transformation (Brambilla et al. 2008; Petit et al. 2020). Surface buoyancy loss along the Gulf Stream and NAC also results in large entrainment rates due to the lateral transfer of fluid from the thermocline to the mixed layer-a process referred to as negative subduction (Marshall et al. 1993) or alternatively induction (Williams et al. 2006). Neither water mass transformation rates nor induction fluxes are calculated here. The homogenized water seen south of the ridge is consistent with Desbruyères et al. (2013) and Burkholder and Lozier (2014), who find that subtropical and subpolar waters share similar hydrographic properties in the eastern SPNA. At the Iceland-Scotland Ridge, the only water that is distinguishable from the otherwise well-mixed inflow in our analysis is water coming from the Nordic seas East source region, which is distinctly colder and fresher.

Despite the Nordic seas inflow being well mixed in properties, we find interannual variability in transport weighted temperature at the Iceland-Scotland Ridge of roughly $\pm 0.5^{\circ} \mathrm{C}$ (Fig. 3b), consistent with observed temperature variability along the NAC (e.g., Arthun et al. 2017). The interannual temperature variability could result from variability in the source region fraction (Fig. 5) due to dynamical shifts in the advective pathways (such as meridional shifts of the NAC or zonal shifts of the Subpolar Front) leading to a larger fraction of subtropical water going into the mix and increasing temperature and salinity (Hátún et al. 2005; Desbruyères et al. 2021). Temperature variability could also be related to anomalous air-sea heat fluxes and variable mixed layer depths associated with atmospheric variability (Desbruyères et al. 2015; Thierry et al. 2008). Additionally, variability in volume transport is important for the heat transport into the Nordic seas 
a)

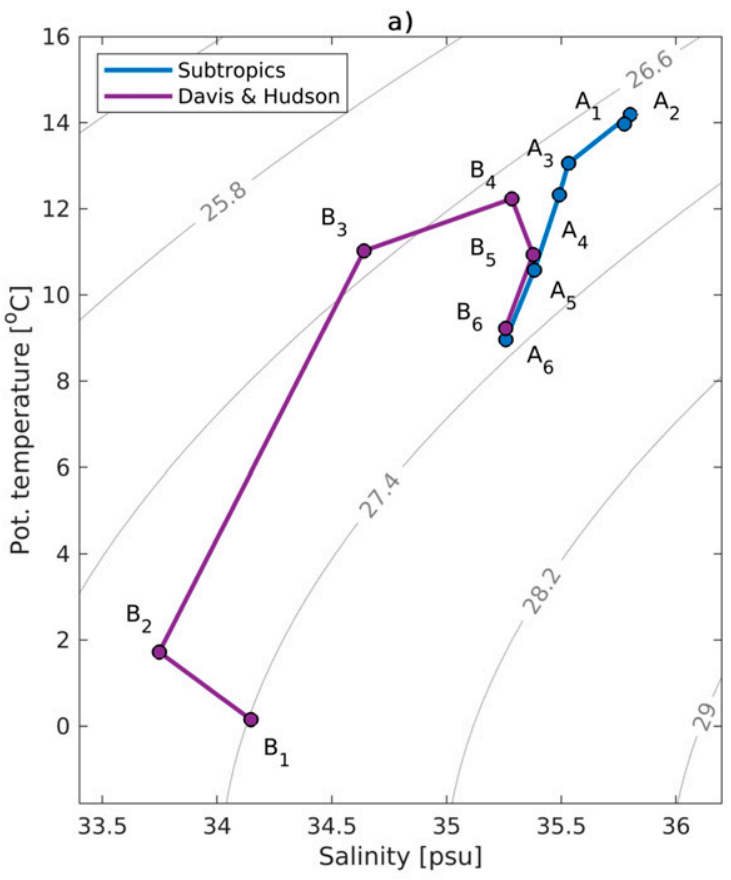

b) Subtropics

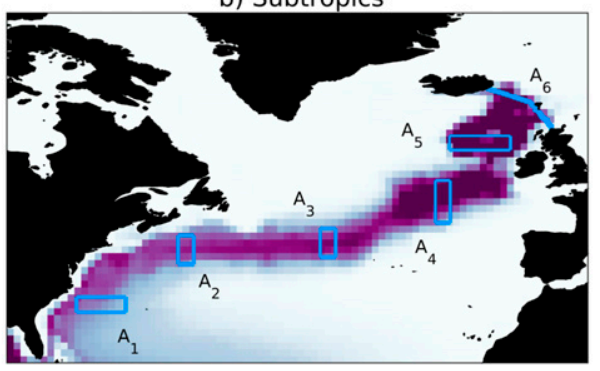

c) Davis \& Hudson

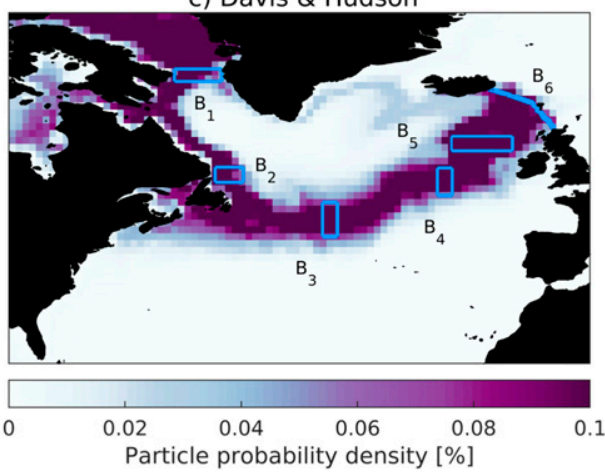

FIG. 8. Along-path $T-S$ properties. (a) Median potential temperature and salinity for particles in the boxes along the (b) "subtropics" and (c) "Davis and Hudson Straits" advective pathways. Only particles at depths shallower than $1000 \mathrm{~m}$ are considered when computing the median particle properties. Median particle transit time from each box to the Iceland-Scotland Ridge is $\mathrm{A}_{1}: 5$ years; $\mathrm{A}_{2}: 3$ years and 4 months; $\mathrm{A}_{3}: 2$ years and 6 months; $\mathrm{A}_{4}: 18$ months; $\mathrm{A}_{5}: 9$ months; $\mathrm{B}_{1}: 3$ years and 11 months; $\mathrm{B}_{2}: 2$ years and 11 months; $\mathrm{B}_{3}: 23$ months; $B_{4}: 13$ months; $\mathrm{B}_{5}: 8$ months.

(Asbjørnsen et al. 2019). In the following sections we will assess some of these potential mechanisms in detail.

\section{Volume transport variability across the ridge}

Volume transport variability has previously been found to dominate heat transport variability in the Nordic seas inflow region (Orvik and Skagseth 2005; Asbjørnsen et al. 2019). We find an interannual inflow variability $\left(\sigma_{\mathrm{VT}_{\mathrm{IN}}}\right)$ of $0.54 \mathrm{~Sv}$ (Fig. 3a), consistent with observed variability (e.g., Bringedal et al. 2018). The transport of subtropical water masses is strongly correlated with the total inflow transport (Table 1; $r=0.85$ ). As a result, variable volume transport of subtropical water is likely a main driver of heat transport variability at the ridge. Also, transport from the Davis and Hudson Straits and the residual SPNA reservoir is significantly correlated to the total inflow transport $(r=0.60$ and $r=0.72$, respectively). The covariability between the transport time series of the different source waters indicates that local wind forcing at the ridge is important for the overall volume transport variability.

While high volume transport at the Iceland-Scotland Ridge implies high heat transport into the Nordic seas, changes in the inflow fraction from the different source regions or substantial shifts in the advective pathways (section 7) can potentially contribute to change the TS properties of the well-mixed inflow. The hypothesis that the relative supply of subpolar and subtropical water determines the temperature and salinity of the Nordic seas inflow (e.g., Hátún et al. 2005; Koul et al. 2020) is somewhat supported by our analysis. The fraction of subtropical water in the inflow is significantly correlated with salinity variability at the ridge (Table $1 ; r=0.53$ ). In terms of

TABLE 1. Correlations between inflow properties [annual mean volume transport (VT), transport-weighted temperature (TWT), transport-weighted salinity (TWS)], annual mean volume transport from the different source regions (total and fraction of inflow), and PCs of the EOF analysis in Fig. 10. Boldface font indicates significant correlations at the $95 \%$ confidence level.

\begin{tabular}{lrrr}
\hline \hline & $\mathrm{VT}_{\mathrm{IN}}$ & $\mathrm{TWT}_{\mathrm{IN}}$ & $\mathrm{TWS}_{\mathrm{IN}}$ \\
\hline $\mathrm{VT}_{\mathrm{IN}}$ & - & 0.22 & 0.21 \\
$\mathrm{VT}_{\mathrm{STR}}$ & $\mathbf{0 . 8 5}$ & 0.31 & $\mathbf{0 . 4 6}$ \\
$\mathrm{VT}_{\mathrm{DH}}$ & $\mathbf{0 . 6 0}$ & -0.17 & -0.27 \\
$\mathrm{VT}_{\mathrm{DEN}}$ & 0.09 & $\mathbf{- 0 . 6 8}$ & $\mathbf{- 0 . 6 2}$ \\
$\mathrm{VT}_{\mathrm{NOR}}$ & 0.02 & $\mathbf{0 . 4 2}$ & 0.07 \\
$\mathrm{VT}_{\mathrm{RES}}$ & $\mathbf{0 . 7 2}$ & 0.19 & 0.13 \\
$\mathrm{VT}_{\mathrm{STR}} / \mathrm{VT}_{\mathrm{IN}}$ & -0.09 & 0.19 & $\mathbf{0 . 5 3}$ \\
$\mathrm{VT}_{\mathrm{DH}} / \mathrm{VT}_{\mathrm{IN}}$ & 0.24 & -0.31 & $\mathbf{- 0 . 4 2}$ \\
$\mathrm{VT}_{\mathrm{DEN}} / \mathrm{VT}_{\mathrm{IN}}$ & -0.11 & $\mathbf{- 0 . 7 2}$ & $\mathbf{- 0 . 6 5}$ \\
$\mathrm{VT}_{\mathrm{NOR}} / \mathrm{VT}_{\mathrm{IN}}$ & -0.25 & 0.34 & 0.00 \\
$\mathrm{VT}_{\mathrm{RES}} / \mathrm{VT}_{\mathrm{IN}}$ & $\mathbf{0 . 3 8}$ & 0.13 & 0.05 \\
$\mathrm{VT}_{\mathrm{DH}}+\mathrm{VT}_{\mathrm{DEN}}+\mathrm{VT}_{\mathrm{RES}} / \mathrm{VT}_{\mathrm{IN}}$ & 0.28 & $\mathbf{- 0 . 4 5}$ & $\mathbf{- 0 . 5 1}$ \\
$\mathrm{PC}_{\mathrm{STR}}$ & -0.02 & $\mathbf{0 . 3 8}$ & $\mathbf{0 . 4 2}$ \\
$\mathrm{PC}_{\mathrm{STR}}$ & -0.10 & $\mathbf{0 . 4 1}$ & 0.27 \\
$\mathrm{PC}_{\mathrm{DH}}$ & $\mathbf{0 . 4 2}$ & $\mathbf{- 0 . 4 4}$ & -0.27 \\
$\mathrm{PC}_{\mathrm{DH}}$ & 0.18 & 0.12 & 0.07 \\
\hline
\end{tabular}




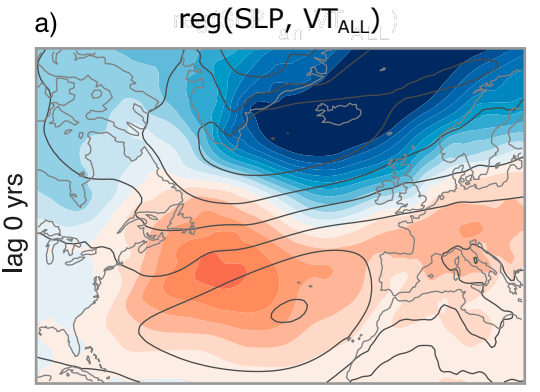

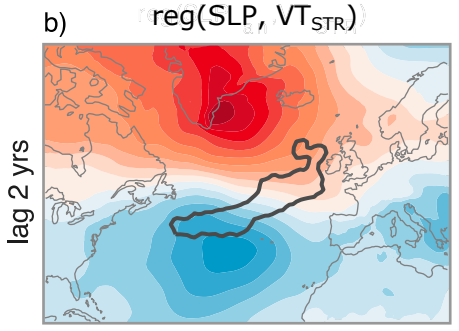

d)

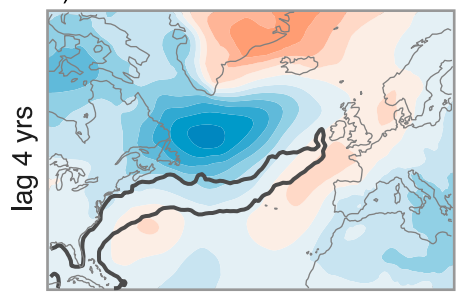

c) $\quad \operatorname{reg}\left(\mathrm{SLP}, \mathrm{VT}_{\mathrm{DH}}\right)$

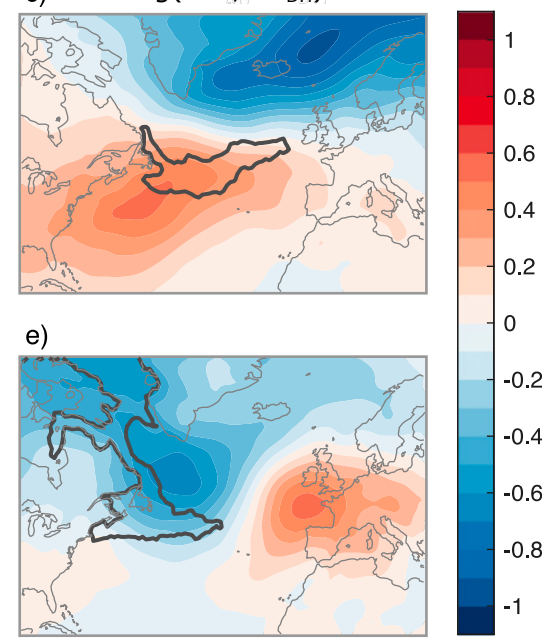

FIG. 9. SLP regressed onto inflow transport. ERA-Interim annual mean sea level pressure (SLP; hPa) regressed onto interannual volume transport variability (VT; Sv) at the Iceland-Scotland Ridge. Unit is hPa per standard deviation of volume transport. The volume transport time series has been normalized $\left[\left(X-\mu_{x}\right) / \sigma_{x}\right]$ for comparable magnitudes between the panels. (a) Gray contour lines show the climatological annual mean SLP pattern (contour interval: every $3 \mathrm{hPa}$ from 1007 to $1022 \mathrm{hPa}$ ). At (b), (c) 2- and (d),(e) 4-yr lag times, (b),(d) $60 \%$ of the subtropical particles and (c),(e) $60 \%$ of the Davis-Hudson particles have a position within the black contour lines shown in each panel.

temperature variability, no significant relationship is found with the inflow fraction of subtropical water. However, a large fraction of subpolar and Arctic-origin water is linked to a colder and fresher inflow, mostly arising from significant relationships between inflow properties and the inflow fraction from the Denmark Strait source region (Table 1). The fractions of subtropical and subpolar-/Arctic-origin water $(\mathrm{DH}+\mathrm{DEN}+\mathrm{RES})$ are anticorrelated $(r=-0.68)$, as one might expect given that they together make up most of the inflow. However, the relationship mainly arises from an anticorrelation between the subtropical fraction and the residual fraction (RES; $r=-0.65$ ). This result indicates that an increased inflow fraction of subtropical water happens at the expense of the reservoir of water circulating in the SPNA. The residual fraction is not related to any particular change in the inflow temperature or salinity (Table 1).

\section{Pathway shifts and associated atmospheric forcing}

Each particle experiences multiple years of atmospheric forcing before reaching the ridge, something that influences circulation strength along the advective pathways, as well as the individual trajectories the particles take. To provide insight into the atmospheric forcing associated with variability in volume transport, temperature, and salinity at the Iceland-Scotland Ridge, we regress annual mean sea level pressure (SLP) onto inflow volume transport variability at the ridge with no lag, a 2-yr lag, and a 4-yr lag (Fig. 9). The major features in Fig. 9 discussed in the following text are significant at the $90 \%$ confidence level (Ebisuzaki 1997). Furthermore, to assess zonal and meridional shifts in the advective pathways associated with the identified atmospheric forcing patterns, we perform an empirical orthogonal function (EOF) analysis of particle probability densities (Fig. 10), following the approach of Kelly et al. (2019). As in Fig. 4, the particle probability density distributions underlying the EOF analysis in Fig. 10 are computed from particle positions throughout the 10 years of tracking. However, in contrast to Fig. 4, the particles are additionally grouped by the year they reach the ridge. As a result, the EOF analysis is performed on particle probability densities that contain both temporal and spatial information of particle positions.

At the time of inflow (lag 0), the regression pattern in Fig. 9a resembles an $\mathrm{NAO}^{+}$pattern with a strengthened climatological Icelandic low and a strengthened climatological Azores high. The pattern thus indicates that a high inflow transport across the ridge is associated with $\mathrm{NAO}^{+}$wind forcing. Periods with $\mathrm{NAO}^{+}$conditions are typically associated with strengthened westerlies, a northeastward shift of the storm tracks, and increased storm activity in northwestern Europe (Hurrell 1995). The relationship between a high inflow and $\mathrm{NAO}^{+}$is well known from previous studies (e.g., Zhang et al. 2004; Chafik 2012; Sand $\varnothing$ et al. 2012; Bringedal et al. 2018) and is connected to an Ekman response to strengthened southwesterlies leading to increased sea surface height (SSH) near Shetland and an anomalously strong SSH gradient across the FaroeShetland Channel (Chafik 2012). As an example, 2010 was a year with an exceptionally strong $\mathrm{NAO}^{-}$pattern (Fig. S1) and a noticeably low inflow across the ridge (Fig. 5).

Two years before reaching the ridge, particles of subtropical origin are in the NAC (Fig. 9b). The regression pattern associated with flow from the subtropics shows that a high inflow of subtropical water is linked to a weakened climatological SLP pattern two years prior. The pattern gives a negative wind stress curl anomaly over the SPNA, often linked to a weakened and westward contracted SPG (Häkkinen et al. 2011). Such an 

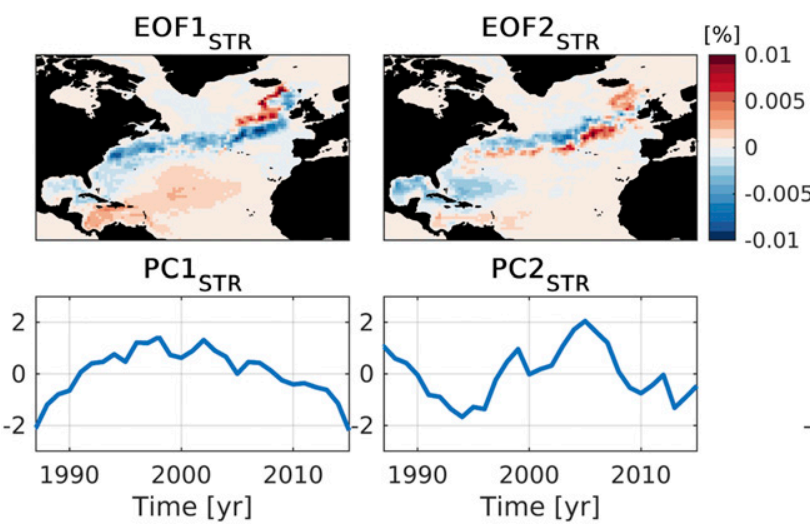
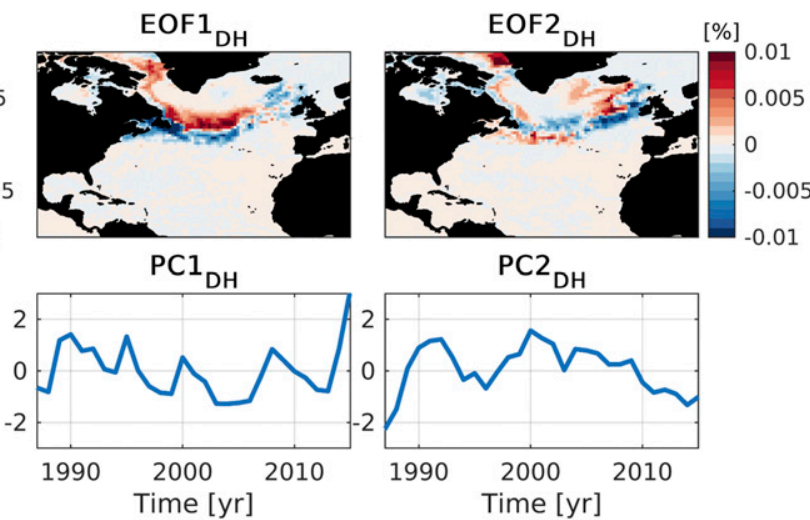

FIG. 10. EOF analysis of particle probability densities for particles coming from the subtropics (STR) and the Davis and Hudson Straits (DH). EOF1 $1_{\text {STR }}$ explains $24 \%$ and EOF2 $2_{\text {STR }}$ explains $15 \%$ of the variability. EOF $1_{\mathrm{DH}}$ explains $21 \%$ and EOF $2_{\mathrm{DH}}$ explains $16 \%$ of the variability. Particles are grouped by the year they reach the ridge, and particle positions are binned into histograms and normalized (as in Fig. 4) prior to the EOF analysis. (bottom) The corresponding principal components (PCs) display the year the particles reach the ridge on the $x$ axes, but the EOF patterns reflect the particle pathways during the full 10 years of tracking.

east-west shift of the Subpolar Front is captured by the leading mode of subtropical particle probability density variability (Fig. 10; $\mathrm{EOF} 1_{\mathrm{STR}}$ ), indicating that particles from the subtropics crossing the ridge in the late 1990s and early 2000s had experienced a westward-shifted Subpolar Front in the years immediately prior to arriving at the ridge. A westward shift of the Subpolar Front gives subpolar-/Arctic-origin water less access to the eastern SPNA, and is associated with a warmer and more saline inflow (Table 1). Shifts in the Subpolar Front are also reflected by the position of the 35.3 isohaline for the upper $500 \mathrm{~m}$, with, for example, an eastward shift in the Rockall Trough region in 2015 compared to in 2000 (Fig. 11; Holliday et al. 2020). The first principal component of the subtropical particle probability density distribution (Fig. 10; $\mathrm{PC} 1_{\mathrm{STR}}$ ) furthermore resembles the preferred SPG indices in Koul et al. (2020) (based on either subsurface density or principal component analysis of sea surface height), reflecting a relatively weak SPG during the early 2000s followed by a strengthening. The low-frequency changes in $\mathrm{PC}_{\mathrm{STR}}$ suggest that the shift of the Subpolar Front experienced by the subtropical particles is not just an immediate response to wind forcing, but rather reflective of more dynamical changes (e.g., Eden and Jung 2001). Consistent with a delayed effect of atmospheric forcing on ocean circulation, $\mathrm{PC}_{\mathrm{STR}}$ is significantly correlated with the NAO index accumulated over the 10 years prior $(r=0.61)$.

The particles coming from the Davis and Hudson Straits are in the northern branch of the NAC two years prior to reaching the ridge (Fig. 9c). The atmospheric circulation anomaly associated with flow from the Davis-Hudson Straits (Fig. 9c) distinctly differs from the atmospheric circulation anomaly associated with flow from the subtropics (Fig. 9b), indicating that different atmospheric forcing patterns act to transport Arctic-origin water versus subtropical water toward the ridge. The $\mathrm{NAO}^{+}$-like pattern seen in Fig. 9c corresponds to a positive wind stress curl anomaly over the SPNA, which in Holliday et al. (2020) was suggested to result in the rerouting of fresh Labrador Current water off the continental shelf and into the subpolar basins during 2012-16. This mechanism is consistent with the leading mode of Davis-Hudson particle probability density variability (Fig. 10; EOF $1_{\mathrm{DH}}$ ), which shows a shifted gyre boundary in the northwestern SPNA that can be interpreted as the Labrador Current following either a primary pathway along the coast or into the subpolar basins. The first principal component of the Davis-Hudson particle probability density distribution (Fig. 10; $\mathrm{PC}_{\mathrm{DH}}$ ) shows a strong positive phase of this pattern for water crossing the ridge in 2015. In 2015 , and in the years prior, we find a eastward migration of the 34.7 isohaline for the upper $500 \mathrm{~m}$ in the Grand Banks region (Fig. 11), which is consistent with fresh water being rerouted off the coast during this period. The second principal component of the Davis-Hudson probability density distribution $\left(\mathrm{PC} 2_{\mathrm{DH}}\right)$ and first principal component of subtropical particle probability density distribution $\left(\mathrm{PC}_{\mathrm{STG}}\right)$ indicate that water reaching the ridge in 2015 had also experienced a southeastward shift of the Subpolar Front in the eastern SPNA, consistent with an expanded SPG. The volume transport of subpolar-/Arctic-origin water at the ridge was furthermore

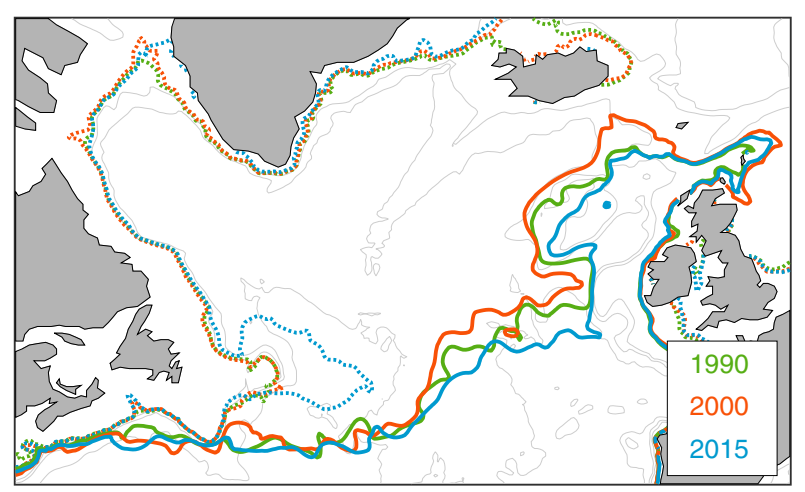

FIG. 11. Subpolar Front location expressed by the annual mean location of the 34.7 (dashed) and 35.3 (solid) isohalines in the upper $500 \mathrm{~m}$ in selected years. Shifts in the location of the 34.7 and 35.3 isohalines illustrate circulation shifts in the western and eastern SPNA, respectively. 
anomalously high in 2015 (Fig. 5), which contributed to an overall high inflow volume transport and cold temperatures (Fig. 3).

Four years before reaching the Iceland-Scotland Ridge, around half of the subtropical particles are located south of $32^{\circ} \mathrm{N}$, while the rest are in the NAC (Fig. 9d). The particles coming from the Davis and Hudson Straits are in Baffin Bay north of the Davis Strait, or in the Labrador Current (Fig. 9e). The atmospheric circulation anomaly associated with flow from the Davis and Hudson Straits at lag 4 years shows a cyclonic anomaly over Baffin Bay and the Canadian Arctic Archipelago (CAA), which has previously been linked to higher CAA transports feeding the Baffin Island Current (Wekerle et al.2013). The cyclonic anomaly also likely sets up an onshore Ekman transport, enhancing the southward export of the Arctic-origin water in the Baffin Island Current.

The atmospheric circulation anomaly associated with flow from the subtropics at lag 4 years displays a cyclonic anomaly in the intergyre region, which is typically associated with an equatorward shift of the NAC (e.g., Marshall et al. 2001). Such meridional shifts of the NAC are captured by the second mode of subtropical particle probability density variability (Fig. 10; EOF2 $2_{\text {STR }}$ ), where an equatorward-shifted NAC is furthermore found to correlate with a warmer Nordic seas inflow (Table 1; $r=0.41$ ). A possible explanation could be that subtropical particles taking a more southerly route experience less lateral mixing with the colder subpolar water while in the NAC. An equatorward-shifted NAC is, however, not associated with an increased inflow of subtropical water at the ridge (Table 1). We therefore speculate that the cyclonic SLP anomaly in the intergyre region associated with a high transport of subtropical water at the ridge 4 years later (Fig. 9d) causes a southwestward shift of the climatological Icelandic low, which enhances the southwest-northeast tilt of the NAC and results in a more direct advective pathway to the ridge for subtropical water.

\section{Discussion and conclusions}

In this study, interannual variability in the Nordic seas inflow between 1986 and 2015 has been scrutinized using Lagrangian methods. Two main research questions were posed regarding 1) the main advective pathways of the Nordic seas inflow and variability therein and 2) the mechanisms behind a cold and fresh inflow versus a warm and saline inflow.

In line with previous studies (e.g., McCartney and Mauritzen 2001; Daniault et al. 2016), water from the subtropics supplied by the NAC is found to be the main component of the Nordic seas inflow (Fig. 4a). On average, $64 \%$ of the annual mean inflow comes from the subtropics, while $26 \%$ has a subpolar or Arctic origin, either coming from the Davis Strait, Hudson Bay, Denmark Strait, or circulating within the SPNA for at least 10 years prior to reaching the ridge (Fig. 5). The subtropical water cannot, however, be easily distinguished from the Arctic-origin water in hydrographic properties alone (Fig. 8), something that emphasizes the importance of Lagrangian tracking to identify the upstream source regions. The fraction of subtropical water is consistent with previous Lagrangian studies looking at the sources of waters in the eastern SPNA (Koul et al. 2020; Burkholder and Lozier 2014), while our
subpolar/Arctic fraction is somewhat larger because we also include the Denmark Strait and the particles circulating in the SPNA in our estimate.

Pronounced interannual variability in the inflow volume transport and the relative fraction of source waters is found (Fig. 3, Fig. S2), which ultimately causes variability in the heat transport into the Nordic seas. We propose a threefold explanation for years of high (low) transport of Arctic-origin water: 1) the ability of regional wind patterns to export water from the CAA and through the Davis Strait, 2) enhanced (weakened) positive wind stress curl over the SPNA routing the exported water off (along) the continental shelf, and 3) the local response to the NAO at the time of inflow pushing more (less) water across the ridge (Fig. 9a). In 2015, all three mechanisms, acting at appropriate times in the preceding few years, led to a high transport (5\% more than average) of subpolar/Arctic-origin water across the ridge (Fig. 10, Figs. S1 and S2). The route taken by the water exported through the Davis Strait is consistent with the circulation shown in Holliday et al. (2020) to be a main mechanism for the record-breaking freshening of the SPNA between 2012 and 2016. While we are unable to quantify the contribution of the different circulation shifts seen in the EOF analysis to specific freshening and cooling events in the SPNA, we do find a robust statistical link between the positive phase (as in 2015) of the leading mode of Davis-Hudson particle probability density variability (Fig. 10; $\mathrm{EOF} 1_{\mathrm{DH}}$ ), a high inflow of Arctic-origin water (total and relative), and a colder and fresher inflow (Table 1).

The transport of subtropical water toward the ridge is also influenced by anomalous atmospheric circulation. A cyclonic SLP anomaly in the intergyre region results in increased transport from the subtropics, giving a high inflow of subtropical water at the Iceland-Scotland Ridge 4-5 years later (Fig. 9d). A negative wind stress curl anomaly over the SPNA when the subtropical water is in the NAC is associated with a high inflow of subtropical water 2 years later, consistent with a weak and westward-contracted SPG (Häkkinen et al. 2011). As for the Arctic-origin water, the local response to the NAO at the time of inflow is important for the overall inflow of subtropical water. High transport of subtropical water (total and relative) is linked to a more saline inflow, while a significant relationship between the volume transport of subtropical water at the ridge and inflow temperature is not found. However, a westwardshifted Subpolar Front and an equatorward-shifted NAC, as captured by the first and second mode of subtropical particle probability density variability, respectively (Fig. 10; EOF1 $1_{\mathrm{STG}}$ and $\mathrm{EOF} 2_{\mathrm{STG}}$ ), are circulation patterns linked to a warmer and more saline inflow (Table 1). The results presented here thus demonstrate the importance of gyre dynamics and large-scale wind forcing in affecting the properties and transport of Atlantic water across the Iceland-Scotland Ridge, in agreement with Hátún et al. (2005).

The subtropical water reaching the Iceland-Scotland Ridge is found to travel at subsurface depths, consistent with the limited surface connectivity between the subtropics and the eastern SPNA highlighted in previous Lagrangian studies (Brambilla and Talley 2006; Burkholder and Lozier 2014; Foukal and Lozier 2016). The propagation of SST anomalies 
along the Atlantic water pathway from the Gulf Stream to the Nordic seas, seen in both observations and models, appears contradictory to this lack of intergyre connectivity at the surface, and has therefore been much debated (e.g., Sutton and Allen 1997; Foukal and Lozier 2016; Årthun et al. 2017). We find a median particle transit time from the subtropics to the Iceland-Scotland Ridge that corresponds to a speed of $4-5 \mathrm{~cm} \mathrm{~s}^{-1}$ (Fig. 6), which is in the range of the estimated propagation speed of thermohaline anomalies (Sutton and Allen 1997; Chepurin and Carton 2012; Årthun et al. 2017). However, the limited surface connectivity found suggests that seasonal reemergence of subsurface temperature anomalies when water is reentrained into the mixed layer during fall and winter (e.g., Timlin et al. 2002; Grist et al. 2019) is likely needed to explain the propagating SST anomalies seen in previous studies.

The results presented here have implications for the predictability of the Nordic seas inflow and the downstream impacts on, for instance, Norwegian Sea heat content (Asbjørnsen et al. 2019), Arctic sea ice (Onarheim et al. 2015), and polar ecosystems (Årthun et al. 2018a). Thermohaline anomalies progressing along the NAC are potentially a major source of predictability, but their usefulness depends on the Lagrangian particles' ability to retain anomalous characteristics along the advective pathways, which requires further study. The predictability of volume transport across the Iceland-Scotland Ridge is limited because of the inability to predict local wind forcing at the ridge, which is strongly related to the NAO (e.g., Dunstone et al. 2016). Recent efforts have, however, shown that the NAO might be more predictable on longer time scales than previously thought (Smith et al. 2020). This could potentially translate into prediction skill for the Nordic seas inflow. The different atmospheric patterns causing variable circulation strength along the identified advective pathways (Fig. 9), can potentially be used as indicators of the inflow volume transport across the ridge at a later stage, due to the time lag. The dynamical shifts in the position of the NAC and the Subpolar Front seen on decadal time scales (Fig. 10; PC1 $1_{\text {STR }}$ and $\mathrm{PC}_{\mathrm{STR}}$ ) and the link to hydrographic properties (Table 1) is promising for possible prediction of changes in the temperature and salinity of the Nordic seas inflow.

Acknowledgments. This study was funded by the PATHWAY project (Research Council of Norway; Grant 263223), the BlueAction project (European Union's Horizon 2020 research and innovation program; Grant 727852), and the Trond Mohn Foundation (Grant BFS2018TMT01). Additionally, HLJ was supported by a visiting researcher grant from the Research Council of Norway (Grant 310329). We are grateful to the European Drakkar project, who carried out the hindcast simulation, and to J. M. Molines and C. Talandier, who kindly provided the data. We thank Graeme McGilchrist and Camille Lique for useful discussions on the Lagrangian analysis. We also want to thank three anonymous reviewers for their constructive comments that improved the manuscript.

Data availability statement. The Lagrangian trajectories used in the analysis can be obtained from the lead author. The computational tool ARIANE, developed by B. Blanke and N.
Grima, is available at https://stockage.univ-brest.fr/\% 7Egrima/ Ariane/. The ERA-Interim data are available at https:// www.ecmwf.int/en/forecasts/datasets/archive-datasets/reanalysisdatasets/era-interim/.

\section{REFERENCES}

Årthun, M., T. Eldevik, L. H. Smedsrud, Ø. Skagseth, and R. B. Ingvaldsen, 2012: Quantifying the influence of Atlantic heat on Barents Sea ice variability and retreat. J. Climate, 25, 47364743, https://doi.org/10.1175/JCLI-D-11-00466.1.

,-- E. Viste, H. Drange, T. Furevik, H. L. Johnson, and N. S. Keenlyside, 2017: Skillful prediction of northern climate provided by the ocean. Nat. Commun., 8, 15875, https:// doi.org/10.1038/ncomms15875.

—, B. Bogstad, U. Daewel, N. S. Keenlyside, A. B. Sandø, C. Schrum, and G. Ottersen, 2018a: Climate based multi-year predictions of the Barents Sea cod stock. PLOS ONE, 13, e0206319, https://doi.org/10.1371/journal.pone.0206319.

—, E. W. Kolstad, T. Eldevik, and N. S. Keenlyside, 2018b: Time scales and sources of European temperature variability. Geophys. Res. Lett., 45, 3597-3604, https://doi.org/10.1002/ 2018 GL077401.

Asbjørnsen, H., M. Årthun, Ø. Skagseth, and T. Eldevik, 2019: Mechanisms of ocean heat anomalies in the Norwegian Sea. J. Geophys. Res. Oceans, 124, 2908-2923, https://doi.org/ 10.1029/2018JC014649.

Behrens, E., K. Våge, B. Harden, A. Biastoch, and C. W. Böning, 2017: Composition and variability of the Denmark Strait Overflow Water in a high-resolution numerical model hindcast simulation. J. Geophys. Res. Oceans, 122, 2830-2846, https://doi.org/10.1002/2016JC012158.

Bernard, B., and Coauthors, 2006: Impact of partial steps and momentum advection schemes in a global ocean circulation model at eddy-permitting resolution. Ocean Dyn., 56, 543567, https://doi.org/10.1007/s10236-006-0082-1.

Bersch, M., 2002: North Atlantic Oscillation-induced changes of the upper layer circulation in the northern North Atlantic Ocean. J. Geophys. Res., 107, 3156, https://doi.org/10.1029/ 2001JC000901.

Blanke, B., and S. Raynaud, 1997: Kinematics of the Pacific Equatorial Undercurrent: An Eulerian and Lagrangian approach from GCM results. J. Phys. Oceanogr., 27, 1038-1053, https://doi.org/10.1175/1520-0485(1997)027<1038:KOTPEU> 2.0.CO;2.

Bouillon, S., M. A. M. Maqueda, V. Legat, and T. Fichefet, 2009: An elastic-viscous-plastic sea ice model formulated on Arakawa B and C grids. Ocean Modell., 27, 174-184, https://doi.org/ 10.1016/j.ocemod.2009.01.004.

Bower, A., and Coauthors, 2019: Lagrangian views of the pathways of the Atlantic meridional overturning circulation. J. Geophys. Res. Oceans, 124, 5313-5335, https://doi.org/ 10.1029/2019JC015014.

Brambilla, E., and L. D. Talley, 2006: Surface drifter exchange between the North Atlantic subtropical and subpolar gyres. J. Geophys. Res., 111, C07026, https://doi.org/10.1029/ 2005JC003146.

,-- , and P. E. Robbins, 2008: Subpolar mode water in the northeastern Atlantic: 2. Origin and transformation. J. Geophys. Res., 113, C04026, https://doi.org/10.1029/2006JC004063.

Bringedal, C., T. Eldevik, Ø. Skagseth, M. A. Spall, and S. Østerhus, 2018: Structure and forcing of observed exchanges across the Greenland-Scotland Ridge. J. Climate, 31, 9881-9901, https:// doi.org/10.1175/JCLI-D-17-0889.1. 
Burkholder, K. C., and M. S. Lozier, 2011: Subtropical to subpolar pathways in the North Atlantic: Deductions from Lagrangian trajectories. J. Geophys. Res., 116, C07017, https://doi.org/ 10.1029/2010JC006697.

$\longrightarrow$, and - 2014: Tracing the pathways of the upper limb of the North Atlantic meridional overturning circulation. Geophys. Res. Lett., 41, 4254-4260, https://doi.org/10.1002/2014GL060226.

Chafik, L., 2012: The response of the circulation in the FaroeShetland Channel to the North Atlantic Oscillation. Tellus, 64, 18423, https://doi.org/10.3402/tellusa.v64i0.18423.

— , and T. Rossby, 2019: Volume, heat, and freshwater divergences in the subpolar North Atlantic suggest the Nordic seas as key to the state of the meridional overturning circulation. Geophys. Res. Lett., 46, 4799-4808, https://doi.org/10.1029/ 2019GL082110.

Chepurin, G. A., and J. A. Carton, 2012: Subarctic and Arctic sea surface temperature and its relation to ocean heat content 1982-2010. J. Geophys. Res. Oceans, 117, C06019, https:// doi.org/10.1029/2011JC007770.

Daniault, N., and Coauthors, 2016: The northern North Atlantic Ocean mean circulation in the early 21 st century. Prog. Oceanogr., 146, 142-158, https://doi.org/10.1016/j.pocean.2016.06.007.

de Boisséson, E., V. Thierry, H. Mercier, G. Caniaux, and D. Desbruyères, 2012: Origin, formation and variability of the Subpolar Mode Water located over the Reykjanes Ridge. J. Geophys. Res., 117, C12005, https://doi.org/10.1029/ 2011JC007519.

Dee, D. P., and Coauthors, 2011: The ERA-Interim reanalysis: Configuration and performance of the data assimilation system. Quart. J. Roy. Meteor. Soc., 137, 553-597, https://doi.org/ 10.1002/qj.828.

Desbruyères, D., V. Thierry, and H. Mercier, 2013: Simulated decadal variability of the meridional overturning circulation across the A25-Ovide section. J. Geophys. Res. Oceans, 118, 462-475, https://doi.org/10.1029/2012JC008342.

- H. Mercier, and V. Thierry, 2015: On the mechanisms behind decadal heat content changes in the eastern subpolar gyre. Prog. Oceanogr., 132, 262-272, https://doi.org/10.1016/ j.pocean.2014.02.005.

_- L. Chafik, and G. Maze, 2021: A shift in the ocean circulation has warmed the subpolar North Atlantic Ocean since 2016. Commun. Earth Environ., 2, 48, https://doi.org/10.1038/s43247021-00120-y.

Dickson, R. R., J. Meincke, S.-A. Malmberg, and A. J. Lee, 1988: The "great salinity anomaly" in the northern North Atlantic 1968-1982. Prog. Oceanogr., 20, 103-151, https://doi.org/10.1016/ 0079-6611(88)90049-3.

Döös, K., 1995: Interocean exchange of water masses. J. Geophys. Res., 100, 13 499-13 514, https://doi.org/10.1029/95JC00337.

Dunstone, N., D. Smith, A. Scaife, L. Hermanson, R. Eade, N. Robinson, M. Andrews, and J. Knight, 2016: Skilful predictions of the winter North Atlantic Oscillation one year ahead. Nat. Geosci., 9, 809-814, https://doi.org/10.1038/ ngeo2824.

Dussin, R., B. Barnier, L. Brodeau, and J. M. Molines, 2016: The making of the DRAKKAR forcing set DFS5. Laboratoire de Glaciologie et Géophysique de l'Environnement Tech. Rep., 34 pp., https://www.drakkar-ocean.eu/publications/reports/ report_DFS5v3_April2016.pdf.

Ebisuzaki, W., 1997: A method to estimate the statistical significance of a correlation when the data are serially correlated. J. Climate, 10, 2147-2153, https://doi.org/10.1175/1520-0442(1997) 010<2147:AMTETS >2.0.CO;2.
Eden, C., and T. Jung, 2001: North Atlantic interdecadal variability: Oceanic response to the North Atlantic Oscillation (1865-1997). J. Climate, 14, 676-691, https://doi.org/10.1175/1520-0442(2001) 014<0676:NAIVOR $>2.0 . \mathrm{CO} ; 2$.

, and J. Willebrand, 2001: Mechanism of interannual to decadal variability of the North Atlantic circulation. J. Climate, 14, 2266-2280, https://doi.org/10.1175/1520-0442(2001)014<2266: MOITDV $>2.0 . \mathrm{CO} ; 2$.

Eldevik, T., and J. E. Ø. Nilsen, 2013: The Arctic-Atlantic thermohaline circulation. J. Climate, 26, 8698-8705, https://doi.org/ 10.1175/JCLI-D-13-00305.1.

Foukal, N. P., and M. S. Lozier, 2016: No inter-gyre pathway for sea-surface temperature anomalies in the North Atlantic. Nat. Commun., 7, 11333, https://doi.org/10.1038/ncomms11333.

Fratantoni, D. M., 2001: North Atlantic surface circulation during the 1990's observed with satellite-tracked drifters. J. Geophys. Res., 106, 22 067-22 093, https://doi.org/10.1029/2000JC000730.

Gillard, L. C., X. Hu, P. G. Myers, and J. L. Bamber, 2016: Meltwater pathways from marine terminating glaciers of the Greenland ice sheet. Geophys. Res. Lett., 43, 10 873-10 882, https://doi.org/10.1002/2016GL070969.

Glessmer, M. S., T. Eldevik, K. Våge, J. E. Øie Nilsen, and E. Behrens, 2014: Atlantic origin of observed and modelled freshwater anomalies in the Nordic seas. Nat. Geosci., 7, 801805, https://doi.org/10.1038/ngeo2259.

Grégorio, S., T. Penduff, G. Sérazin, J.-M. Molines, B. Barnier, and J. Hirschi, 2015: Intrinsic variability of the Atlantic meridional overturning circulation at interannual-to-multidecadal time scales. J. Phys. Oceanogr., 45, 1929-1946, https://doi.org/ 10.1175/JPO-D-14-0163.1.

Grist, J. P., and Coauthors, 2019: Re-emergence of North Atlantic subsurface ocean temperature anomalies in a seasonal forecast system. Climate Dyn., 53, 4799-4820, https://doi.org/ 10.1007/s00382-019-04826-w.

Häkkinen, S., P. B. Rhines, and D. L. Worthen, 2011: Warm and saline events embedded in the meridional circulation of the northern North Atlantic. J. Geophys. Res., 116, C03006, https://doi.org/10.1029/2010JC006275.

Hansen, B., and S. Østerhus, 2000: North Atlantic-Nordic seas exchanges. Prog. Oceanogr., 45, 109-208, https://doi.org/10.1016/ S0079-6611(99)00052-X.

Hátún, H., A. B. Sand $\varnothing$, H. Drange, B. Hansen, and H. Valdimarsson, 2005: Influence of the Atlantic Subpolar Gyre on the thermohaline circulation. Science, 309, 1841-1844, https://doi.org/10.1126/ science.1114777.

, and Coauthors, 2009: Large bio-geographical shifts in the north-eastern Atlantic Ocean: From the subpolar gyre, via plankton, to blue whiting and pilot whales. Prog. Oceanogr., 80, 149-162, https://doi.org/10.1016/j.pocean.2009.03.001.

Herbaut, C., and M.-N. Houssais, 2009: Response of the eastern North Atlantic subpolar gyre to the North Atlantic Oscillation. Geophys. Res. Lett., 36, L17607, https://doi.org/10.1029/ 2009GL039090.

Heuzé, C., and M. Årthun, 2019: The Atlantic inflow across the Greenland-Scotland Ridge in global climate models (CMIP5). Elementa, 7, 16, https://doi.org/10.1525/elementa.354.

Holliday, N. P., and Coauthors, 2020: Ocean circulation causes the largest freshening event for 120 years in eastern subpolar North Atlantic. Nat. Commun., 11, 585, https://doi.org/10.1038/ s41467-020-14474-y.

Houpert, L., M. E. Inall, E. Dumont, S. Gary, C. Johnson, M. Porter, W. E. Johns, and S. A. Cunningham, 2018: Structure and transport of the North Atlantic Current in the 
eastern subpolar gyre from sustained glider observations. J. Geophys. Res. Oceans, 123, 6019-6038, https://doi.org/ 10.1029/2018JC014162.

Hurrell, J. W., 1995: Decadal trends in the North Atlantic Oscillation: Regional temperatures and precipitation. Science, 269, 676-679, https://doi.org/10.1126/science.269.5224.676.

Jones, B. T., A. Solow, and R. Ji, 2016: Resource allocation for Lagrangian tracking. J. Atmos. Oceanic Technol., 33, 12251235, https://doi.org/10.1175/JTECH-D-15-0115.1.

Kelly, S. J., A. Proshutinsky, E. K. Popova, Y. K. Aksenov, and A. Yool, 2019: On the origin of water masses in the Beaufort Gyre.J. Geophys. Res. Oceans, 124, 4696-4709, https://doi.org/ 10.1029/2019JC015022.

Kenigson, J. S., and M.-L. Timmermans, 2021: Nordic seas hydrography in the context of Arctic and North Atlantic Ocean dynamics. J. Phys. Oceanogr., 51, 101-114, https://doi.org/ 10.1175/JPO-D-20-0071.1.

Koul, V., and Coauthors, 2020: Unraveling the choice of the North Atlantic subpolar gyre index. Sci. Rep., 10, 1005, https:// doi.org/10.1038/s41598-020-57790-5.

Lique, C., A. M. Treguier, B. Blanke, and N. Grima, 2010: On the origins of water masses exported along both sides of Greenland: A Lagrangian model analysis. J. Geophys. Res., 115, C05019, https://doi.org/10.1029/2009JC005316.

MacGilchrist, G. A., D. P. Marshall, H. L. Johnson, C. Lique, and M. Thomas, 2017: Characterizing the chaotic nature of ocean ventilation. J. Geophys. Res. Oceans, 122, 7577-7594, https:// doi.org/10.1002/2017JC012875.

Madec, G., and Coauthors, 2016: NEMO ocean engine. Note du Pôle de modélisation, Institut Pierre-Simon Laplace, 396 pp., https:// www.nemo-ocean.eu/wp-content/uploads/NEMO_book.pdf.

Marsh, R., I. D. Haigh, S. A. Cunningham, M. E. Inall, M. Porter, and B. I. Moat, 2017: Large-scale forcing of the European Slope Current and associated inflows to the North Sea. Ocean Sci., 13, 315-335, https://doi.org/10.5194/os-13-315-2017.

Marshall, J., R. G. Williams, and A. J. Nurser, 1993: Inferring the subduction rate and period over the North Atlantic. J. Phys. Oceanogr., 23, 1315-1329, https://doi.org/10.1175/1520-0485(1993) $023<1315$ :ITSRAP $>2.0$. CO; 2 .

—, H. Johnson, and J. Goodman, 2001: A study of the interaction of the North Atlantic Oscillation with ocean circulation. J. Climate, 14, 1399-1421, https://doi.org/10.1175/1520-0442(2001) 014<1399:ASOTIO>2.0.CO;2.

McCartney, M. S., and C. Mauritzen, 2001: On the origin of the warm inflow to the Nordic seas. Prog. Oceanogr., 51, 125-214, https://doi.org/10.1016/S0079-6611(01)00084-2.

Mork, K. A., Ø. Skagseth, V. Ivshin, V. Ozhigin, S. L. Hughes, and H. Valdimarsson, 2014: Advective and atmospheric forced changes in heat and fresh water content in the Norwegian Sea, 1951-2010. Geophys. Res. Lett., 41, 6221-6228, https://doi.org/ 10.1002/2014GL061038.

,$- \ldots$, and H. Søiland, 2019: Recent warming and freshening of the Norwegian Sea observed by Argo data. J. Climate, 32, 3695-3705, https://doi.org/10.1175/JCLI-D-18-0591.1.

Olsen, S. M., B. Hansen, S. Østerhus, D. Quadfasel, and H. Valdimarsson, 2016: Biased thermohaline exchanges with the Arctic across the Iceland-Faroe Ridge in ocean climate models. Ocean Sci., 12, 545-560, https://doi.org/10.5194/os-12545-2016.

Onarheim, I. H., T. Eldevik, M. Årthun, R. B. Ingvaldsen, and L. H. Smedsrud, 2015: Skillful prediction of Barents Sea ice cover. Geophys. Res. Lett., 42, 5364-5371, https://doi.org/ 10.1002/2015GL064359.
Orvik, K. A., and $\varnothing$. Skagseth, 2005: Heat flux variations in the eastern Norwegian Atlantic Current toward the Arctic from moored instruments, 1995-2005. Geophys. Res. Lett., 32, L14610, https://doi.org/10.1029/2005GL023487.

Østerhus, S., and Coauthors, 2019: Arctic Mediterranean exchanges: A consistent volume budget and trends in transports from two decades of observations. Ocean Sci., 15, 379-399, https://doi.org/10.5194/os-15-379-2019.

Petit, T., M. S. Lozier, S. A. Josey, and S. A. Cunningham, 2020: Atlantic deep water formation occurs primarily in the Iceland Basin and Irminger Sea by local buoyancy forcing. Geophys. Res. Lett., 47, e2020GL091028, https://doi.org/10.1029/2020GL091028.

Piecuch, C. G., R. M. Ponte, C. M. Little, M. W. Buckley, and I. Fukumori, 2017: Mechanisms underlying recent decadal changes in subpolar North Atlantic Ocean heat content. J. Geophys. Res. Oceans, 122, 7181-7197, https://doi.org/ 10.1002/2017JC012845.

Qin, X., E. van Sebille, and A. Sen Gupta, 2014: Quantification of errors induced by temporal resolution on Lagrangian particles in an eddy-resolving model. Ocean Modell., 76, 20-30, https:// doi.org/10.1016/j.ocemod.2014.02.002.

Robson, J., P. Ortega, and R. Sutton, 2016: A reversal of climatic trends in the North Atlantic since 2005. Nat. Geosci., 9, 513517, https://doi.org/10.1038/ngeo2727.

Rossby, T., 1996: The North Atlantic Current and surrounding waters: At the crossroads. Rev. Geophys., 34, 463-481, https:// doi.org/10.1029/96RG02214.

Rypina, I. I., L. J. Pratt, and M. S. Lozier, 2011: Near-surface transport pathways in the North Atlantic Ocean: Looking for throughput from the subtropical to the subpolar gyre. J. Phys. Oceanogr., 41, 911-925, https://doi.org/10.1175/2011JPO4498.1.

Sand $\varnothing$, A. B., J. E. Ø. Nilsen, T. Eldevik, and M. Bentsen, 2012: Mechanisms for variable North Atlantic-Nordic seas exchanges. J. Geophys. Res., 117, C12006, https://doi.org/ 10.1029/2012JC008177.

Sarafanov, A., 2009: On the effect of the North Atlantic Oscillation on temperature and salinity of the subpolar North Atlantic intermediate and deep waters. ICES J. Mar. Sci., 66, 14481454, https://doi.org/10.1093/icesjms/fsp094.

Sherwin, T. J., S. L. Hughes, W. R. Turrell, B. Hansen, and S. Østerhus, 2008: Wind-driven monthly variations in transport and the flow field in the Faroe-Shetland Channel. Polar Res., 27, 7-22, https://doi.org/10.1111/j.1751-8369.2007.00036.x.

Smith, D. M., and Coauthors, 2020: North Atlantic climate far more predictable than models imply. Nature, 583, 796-800, https://doi.org/10.1038/s41586-020-2525-0.

Sutton, R. T., and M. R. Allen, 1997: Decadal predictability of North Atlantic sea surface temperature and climate. Nature, 388, 563-567, https://doi.org/10.1038/41523.

- , and B. Dong, 2012: Atlantic Ocean influence on a shift in European climate in the 1990s. Nat. Geosci., 5, 788-792, https://doi.org/10.1038/ngeo1595.

Thierry, V., E. de Boisséson, and H. Mercier, 2008: Interannual variability of the Subpolar Mode Water properties over the Reykjanes Ridge during 1990-2006. J. Geophys. Res., 113, C04016, https://doi.org/10.1029/2007JC004443.

Timlin, M. S., M. A. Alexander, and C. Deser, 2002: On the reemergence of North Atlantic SST anomalies. J. Climate, 15, 2707-2712, https://doi.org/10.1175/1520-0442(2002)015<2707: OTRONA $>2.0 . \mathrm{CO} ; 2$.

Uppala, S. M., and Coauthors, 2005: The ERA-40 Re-Analysis. Quart. J. Roy. Meteor. Soc., 131, 2961-3012, https://doi.org/ 10.1256/qj.04.176. 
Valdivieso Da Costa, M., and B. Blanke, 2004: Lagrangian methods for flow climatologies and trajectory error assessment. Ocean Modell., 6, 335-358, https://doi.org/10.1016/ S1463-5003(03)00023-4.

van Sebille, E., and Coauthors, 2018: Lagrangian ocean analysis: Fundamentals and practices. Ocean Modell., 121, 49-75, https:// doi.org/10.1016/j.ocemod.2017.11.008.

Wagner, P., F. U. Schwarzkopf, I. M. Koszalka, and A. Biastoch, 2019: Can Lagrangian tracking simulate tracer spreading in a high-resolution ocean general circulation model? J. Phys. Oceanogr., 49, 1141-1157, https://doi.org/10.1175/JPO-D-180152.1.

Wekerle, C., Q. Wang, S. Danilov, T. Jung, and J. Schröter, 2013: The Canadian Arctic Archipelago throughflow in a multiresolution global model: Model assessment and the driving mechanism of interannual variability. J. Geophys. Res. Oceans, 118, 4525-4541, https://doi.org/10.1002/jgrc.20330.
Williams, R. G., V. Roussenov, and M. J. Follows, 2006: Nutrient streams and their induction into the mixed layer. Global Biogeochem. Cycles, 20, GB1016, https://doi.org/10.1029/ $2005 \mathrm{~GB} 002586$.

Yeager, S. G., A. R. Karspeck, and G. Danabasoglu, 2015: Predicted slowdown in the rate of Atlantic sea ice loss. Geophys. Res. Lett., 42, 10 704-10 713, https://doi.org/10.1002/ 2015 GL065364.

Zhang, J., M. Steele, D. A. Rothrock, and R. W. Lindsay, 2004: Increasing exchanges at Greenland-Scotland Ridge and their links with the North Atlantic Oscillation and Arctic Sea Ice. Geophys. Res. Lett., 31, L09307, https://doi.org/10.1029/ 2003 GL019304.

Zhao, J., A. Bower, J. Yang, X. Lin, and N. P. Holliday, 2018: Meridional heat transport variability induced by mesoscale processes in the subpolar North Atlantic. Nat. Commun., 9, 1124, https://doi.org/10.1038/s41467-018-03134-x. 
